\title{
Predictors of expiratory flow limitation measured by forced oscillation technique in COPD
}

\author{
Masashi Mikamo ${ }^{1}$, Toshihiro Shirai ${ }^{1 *}$, Kazutaka Mori ${ }^{2}$, Yuichiro Shishido ${ }^{1}$, Takefumi Akita' ${ }^{1}$, Satoru Morita', \\ Kazuhiro Asada ${ }^{1}$, Masato Fujii ${ }^{1}$ and Takafumi Suda ${ }^{2}$
}

\begin{abstract}
Background: Expiratory flow limitation (EFL) during tidal breathing is common in patients with severe COPD, and a major determinant of dynamic hyperinflation and exercise limitation. EFL can be measured by the forced oscillation technique (FOT); however, the relevance to clinical parameters is not fully understood. We hypothesized that emphysema extent and pulmonary function would contribute independently to the degree of EFL.

Methods: Broadband frequency FOT and pulmonary function tests were performed in 74 patients with COPD to derive respiratory system resistance (Rrs) and reactance (Xrs), and the EFL index as expressed by the differences between inspiratory and expiratory phases of Xrs at $5 \mathrm{~Hz}(\Delta \mathrm{X} 5)$. Emphysema extent was measured by high-resolution computed tomography and scored.

Results: On the basis of the median value of $\Delta X 5\left(0.55 \mathrm{cmH}_{2} \mathrm{O} / \mathrm{L} / \mathrm{s}\right)$, patients were classified into a high or low EFL index group. In multivariate regression analyses, a high EFL index was independently predicted by emphysema score, peripheral airway obstruction (forced expiratory flow between $25 \%$ and $75 \%$ of forced vital capacity), hyperinflation (functional residual capacity), and airway caliber (whole-breath Rrs at $5 \mathrm{~Hz}$ ).
\end{abstract}

Conclusions: EFL measured by FOT is a global measure of COPD that has separable etiologies and is useful for evaluating the disease condition.

Keywords: Broadband, COPD, Expiratory flow limitation, Forced oscillation technique, Tidal breathing

\section{Background}

Tidal expiratory flow limitation (EFL) occurs when an increase in transpulmonary pressure causes no increase in resting expiratory flow. This phenomenon is common in patients with severe COPD and is a major determinant of dynamic hyperinflation and exercise limitation [1,2]. Dellacà et al. indicated that the differences between inspiratory and expiratory phases of respiratory system reactance $(\Delta \mathrm{Xrs})$ measured by the forced oscillation technique (FOT) allowed the detection of EFL [1]. It is supposed that Xrs normally reflects the elastic and inertial properties of the respiratory system but, with flow limitation, oscillatory signals cannot pass through the choke points and reach the alveoli. During EFL, respiratory system resistance (Rrs) and Xrs will reflect the mechanical

\footnotetext{
* Correspondence: toshihiro-shirai@i.shizuoka-pho.jp

'Department of Respiratory Medicine, Shizuoka General Hospital, 4-27-1 Kita-Ando, 420-0881 Aoi, Shizuoka, Japan

Full list of author information is available at the end of the article
}

properties of airways proximal to the choke points, which are much stiffer than the periphery, producing a marked reduction in apparent compliance and a fall in Xrs.

In contrast to the monofrequency FOT used by Dellacà et al., clinical application of the broadband frequency FOT has progressed recently with the spread of commercially available devices: the impulse oscillation system (IOS) [3] and MostGraph [4]. Several investigators have reported that $\triangle \mathrm{Xrs}$, the EFL index, could discriminate between COPD and asthma [5-7], and between COPD and pulmonary fibrosis [8]; however, the relevance of EFL to clinical parameters is not fully understood. We hypothesized that emphysema extent and pulmonary function would contribute independently to the degree of EFL in patients with COPD. In this cross-sectional study we measured the EFL index by broadband frequency FOT in 74 patients with COPD and assessed the differences in clinical features between patients with a high and low EFL index. 


\section{Methods}

\section{Subjects}

Seventy-four patients with COPD who attended outpatient clinics at Shizuoka General Hospital for routine check-ups between October 2009 and December 2012 were enrolled in this study. The patients satisfied the definition of the Global Initiative for Chronic Obstructive Lung Disease (GOLD) [9] and had been receiving medications, including long-acting antimuscarinic agents, long-acting $\beta 2$-agonists, inhaled corticosteroids, or sustained-release theophylline. They were clinically stable and had had no exacerbations, defined as increased dyspnea associated with a change in the quality and quantity of sputum, for at least one month before the study.

Thirty-nine healthy control subjects without pulmonary diseases were recruited from our hospital staff. The protocols were approved by the Institutional Review Board of Shizuoka General Hospital (SGH 11-07-20) and informed consent was obtained from all subjects prior to the study.

\section{Modified Medical Research Council (mMRC) and COPD assessment test (CAT)}

The mMRC scale was used to evaluate dyspnea in daily living, grading 0 (only get breathless with strenuous exercise) to 4 (too breathless to leave the house or breathless when dressing) [10].

The CAT (Japanese version, supplied by GlaxoSmithKline Japan) questionnaire consists of 8 items (cough, phlegm, chest tightness, breathlessness going up hills/stairs, activity limitations at home, confidence leaving home, sleep, and energy) assessing and quantifying the symptoms and impacts of COPD [11]. Each item is scored from 0 to 5 giving a total score range from 0 to 40, corresponding to the best and worst health status, respectively.

\section{Measurement of respiratory impedance and pulmonary function tests}

On the same examination day, when their clinical symptoms were stable, measurements of respiratory impedance using FOT and pulmonary function tests were performed in that order. Short-acting $\beta 2$ agonists were not used for more than 12 hours before these tests in every case.

Respiratory impedance was measured with broadband FOT using a commercially available device (MostGraph-01; Chest M.I. Co. Ltd., Tokyo, Japan) [4,7] and met standard recommendations [12]. Impulse oscillatory signals generated by a loud speaker at intervals of 0.25 seconds were applied to the respiratory system through the mouthpiece during tidal breathing at rest. Mouth pressure and flow signals were measured and calculated to obtain Rrs and Xrs properties against oscillatory frequency ranging from 4 to $36 \mathrm{~Hz}$. During measurements, the subjects supported their cheeks firmly to reduce upper airway shunting while sitting with their neck in a comfortable neutral posture.
Since the curves of Rrs and Xrs versus frequency could be obtained every 0.25 seconds, they were serially lined up against the time axis with assigned color gradients, resulting in colored 3-dimensional imaging patterns.

In the present study, we used Rrs at 5 and $20 \mathrm{~Hz}$ (R5 and R20, respectively), and the difference between R5 and R20 (R5-R20) as an indicator of the frequency dependence of Rrs, which is supposed to reflect inhomogeneous ventilatory mechanics [13]. We also used Xrs at $5 \mathrm{~Hz}$ (X5), which reflects elastic and inertial properties of the lung, resonant frequency (Fres) where Xrs crosses zero and the elastic and inertial forces are equal in magnitude and opposite, and a low-frequency reactance area (ALX), which is the integral of Xrs at $5 \mathrm{~Hz}$ to the Fres. Each oscillatory index is expressed as the mean values during a respiratory cycle (whole-breath), inspiratory and expiratory phases, and the differences between inspiratory and expiratory phases $(\Delta)$. In the present study, $\Delta \mathrm{X} 5$ was used as the EFL index. Patients were classified into high or low EFL index groups according to the median value of EFL index.

Spirometry and lung volumes were determined using computerized equipment (model CHESTAC-8800; Chest M.I. Co. Ltd., Tokyo, Japan) according to the recommendations $[14,15]$. Predicted values for pulmonary function tests, excluding inspiratory capacity (IC), were obtained from the Japanese Respiratory Society guidelines [16] and those for IC were obtained from previous reports $[17,18]$.

\section{Emphysema score}

Emphysema was evaluated by high-resolution computed tomography (HRCT) according to the method reported previously $[8,19]$. Briefly, HRCT findings were evaluated at 3 anatomic levels in both lungs: near the superior margin of the aortic arch (level of the upper lung field), at the level of the carina (level of the middle lung field), and at the level of the orifice of the inferior pulmonary veins (level of the lower lung field). Emphysema was defined as a focal region of low attenuation without visible walls. Cysts were defined as round air spaces with a well-defined wall. Emphysema with cysts, if any, was scored visually in the 6 fields and summed. The score in each lung field was calculated according to the percentage of low-attenuation areas (\%LAA): score 0, \%LAA $<5 \%$; score $1, \% \mathrm{LAA} \geq 5 \%-<25 \%$; score 2 , \%LAA $\geq 25 \%-<50 \%$; score 3 , \%LAA $\geq 50 \%-<75 \%$; and score $4, \% \mathrm{LAA} \geq 75 \%$. The threshold level between the normal lung density area and LAA was defined as -950 Hounsfield units on the basis of our previous study [8]. Thus, the total emphysema scores ranged from 0 to 24 .

\section{Statistical analysis}

Comparisons among groups were made using the Kruskal-Wallis test, followed by multiple comparisons among groups using the Mann-Whitney $U$ test. The chi-square or Fisher's exact test was used to test significance 
in group differences with respect to the percentage of patients in various categories. Correlations between variables were performed using the Spearman rank correlation coefficient. Multivariate logistic regression analyses were performed to adjust for effects among multiple variables for elevation of the EFL index $(\Delta X 5)$. Model selection was made by the best subset selection procedure using Akaike's information criteria (AIC). Stat View Version 5.0 (SAS Institute, Cary, NC, USA) and R version 2.15.2 (R Foundation for Statistical Computing, Vienna, Austria, 2012) were used for statistical calculations. A p value of $<0.05$ was considered significant, and all tests were 2 sided.

\section{Results}

The clinical characteristics of the subjects, pulmonary function tests, and forced oscillatory parameters are shown in Tables 1 and 2. The frequency distribution of the EFL index $(\Delta \mathrm{X} 5)$ in 74 patients is shown in Figure 1. According to the median value of $0.55\left(\mathrm{cmH}_{2} \mathrm{O} / \mathrm{L} / \mathrm{s}\right), 74$ patients with COPD were classified into two groups, with 37 patients each with a high and low EFL index. mMRC scale, functional residual capacity (FRC), residual volume (RV), total lung capacity (TLC), and RV/TLC were significantly higher and forced expiratory volume in 1 second (FEV1), forced vital capacity (FVC), FEV1/FVC, IC, and forced expiratory flow between $25 \%$ and $75 \%$ of FVC (FEF 25-75\%) were lower in the high EFL index group than in the low EFL index group. Whole-breath, inspiratory, and expiratory R5, R20, R5-R20, Fres, and ALX, and $\Delta X 5$ were significantly higher and whole-breath, inspiratory, and expiratory $\mathrm{X} 5, \Delta(\mathrm{R} 5-\mathrm{R} 20), \Delta$ Fres, and $\triangle \mathrm{ALX}$ were lower in the high EFL index group than in the low EFL index group. There was no difference in CAT and emphysema scores between the 2 groups. Figure 2 shows typical colored 3-dimensional images of Rrs and Xrs in each representative patient with a high or low EFL index.

The control subjects were significantly younger, with no male dominance, more nonsmokers, fewer pack-years, and

Table 1 Characteristics of the study subjects

\begin{tabular}{|c|c|c|c|c|}
\hline & Patients with COPD $n=74$ & High EFL index group $n=37$ & Low EFL index group $n=37$ & Controls $\mathrm{n}=39$ \\
\hline Age (years) & $73(54-86)$ & $73(62-84)^{*}$ & $73(54-86)^{*}$ & $35(24-69)$ \\
\hline Gender (male/female) & $71 / 3$ & $35 / 2^{*}$ & $36 / 1^{*}$ & $19 / 20$ \\
\hline Body mass index $\left(\mathrm{kg} / \mathrm{m}^{2}\right)$ & $21.1(15.2-32.3)$ & $21.6(15.6-32.3)$ & $20.8(15.2-27.7)$ & $22.0(16.9-30.8)$ \\
\hline Current/ex/never smoker & $9 / 65 / 0$ & $4 / 33 / 0^{*}$ & $5 / 32 / 0^{*}$ & $4 / 9 / 26$ \\
\hline Pack years & $53.1(5.0-150.0)$ & $62.0(5.0-132.0)^{*}$ & $51.3(7.5-150.0)^{*}$ & $0.0(0.0-33.0)$ \\
\hline mMRC scale & $1(0-4)$ & $2(0-4) \dagger$ & $1(0-4)$ & NA \\
\hline CAT score & $12.5(0-32)$ & $14(3-32)$ & $11(0-30)$ & NA \\
\hline Emphysema score & $10(0-23)$ & $12(0-23)$ & $10(0-21)$ & NA \\
\hline GOLD I/II/III/IV & $9 / 31 / 20 / 14$ & $1 / 9 / 15 / 12+$ & $8 / 22 / 5 / 2$ & NA \\
\hline LAMA & 26 & 11 & 15 & NA \\
\hline LABA & 4 & 2 & 2 & NA \\
\hline$L A M A+L A B A$ & 26 & 15 & 11 & NA \\
\hline LAMA + ICS/LABA & 13 & 7 & 6 & NA \\
\hline Sustained-release theophylline & 24 & $18+$ & 6 & NA \\
\hline FEV1 (\% predicted) & $52.6(17.8-108.0)$ & $36.8(17.8-108.0) \dagger^{*}$ & $67.5(20.0-93.8)^{*}$ & $100.0(76.9-118.5)$ \\
\hline FVC (\% predicted) & $81.4(34.9-144.0)$ & $75.6(34.9-144.0) \dagger^{*}$ & $91.4(42.5-114.9)^{*}$ & $102.7(82.5-123.1)$ \\
\hline FEV1/FVC (\%) & $50.1(28.7-69.9)$ & $42.0(28.7-66.8) \dagger^{*}$ & $59.2(30.4-69.9)^{*}$ & $84.2(73.5-97.7)$ \\
\hline IC (\% predicted) & $83.0(38.5-124.8)$ & $78.4(38.5-121.6) \dagger^{*}$ & $86.7(53.6-124.8)$ & $94.2(62.5-146.4)$ \\
\hline FEF $25-75 \%$ (\% predicted) & $18.6(5.7-57.4)$ & $10.1(5.7-37.7)+^{*}$ & $28.5(6.3-57.4)^{*}$ & $83.4(45.8-114.3)$ \\
\hline FRC (\% predicted) & $100.1(56.9-165.5)$ & $111.9(65.4-165.5) \dagger$ & $85.8(56.9-123.4)^{*}$ & $107.9(66.2-138.4)$ \\
\hline RV (\% predicted) & $149.0(34.4-332.0)$ & $182.4(94.0-332.0) \dagger^{*}$ & $133.1(34.4-213.6)^{*}$ & $94.4(65.1-239.6)$ \\
\hline TLC (\% predicted) & $109.0(75.9-152.2)$ & $116.9(76.5-152.2) \dagger$ & $101.5(75.9-133.2)$ & $107.9(84.2-147.5)$ \\
\hline RV/TLC (\% predicted) & $118.2(35.7-180.7)$ & $135.5(71.8-180.7) \dagger^{*}$ & $106.2(35.7-162.9)$ & $112.3(68.7-168.5)$ \\
\hline
\end{tabular}

Values are shown as a median (range) or numbers.

Abbreviations: CAT COPD assessment test, EFL expiratory flow limitation, FEF $25-75 \%$ forced expiratory flow between $25 \%$ and $75 \%$ of FVC, FEV1 forced expiratory volume in 1 second, FRC functional residual capacity, FVC forced vital capacity, GOLD Global Initiative for Chronic Obstructive Lung Disease, IC inspiratory capacity, ICS inhaled corticosteroids, LABA long-acting $\beta 2$-agonists, LAMA long-acting antimuscarinic agents, mMRC modified Medical Research Council, NA not applicable, $R V$ residual volume, $T L C$ total lung capacity.

${ }^{*} \mathrm{p}<0.05$ versus controls, $\mathrm{t} p<0.05$ versus low EFL index group. 
Table 2 Comparison of forced oscillatory parameters

\begin{tabular}{|c|c|c|c|c|c|}
\hline & & $\begin{array}{l}\text { Patients with } \\
\text { COPD } n=74\end{array}$ & $\begin{array}{l}\text { High EFL index } \\
\text { group } \mathrm{n}=37\end{array}$ & $\begin{array}{l}\text { Low EFL index } \\
\text { group } \mathrm{n}=37\end{array}$ & Controls $n=39$ \\
\hline \multirow[t]{4}{*}{$\mathrm{R} 5\left(\mathrm{cmH}_{2} \mathrm{O} / \mathrm{L} / \mathrm{s}\right)$} & Whole breath & $4.36(1.58-8.06)$ & $5.09(2.45-8.06) \dagger^{*}$ & $3.51(1.58-7.99)^{*}$ & $2.79(1.15-5.70)$ \\
\hline & Inspiratory & $3.80(1.57-8.16)$ & $4.80(1.90-8.16) \dagger^{*}$ & $3.11(1.57-7.64)^{*}$ & $2.48(1.01-5.03)$ \\
\hline & Expiratory & $4.78(1.60-10.45)$ & $5.55(2.86-10.45) \dagger^{*}$ & $4.17(1.60-8.34)^{*}$ & $3.04(1.29-6.36)$ \\
\hline & $\Delta \mathrm{R} 5$ & $-0.78(-5.51-0.45)$ & $-0.98(-5.51-0.45)$ & $-0.70(-2.71-0.36)$ & $-0.54(-2.39-0.16)$ \\
\hline \multirow[t]{4}{*}{$\mathrm{R} 2 \mathrm{O}\left(\mathrm{cmH}_{2} \mathrm{O} / \mathrm{L} / \mathrm{s}\right)$} & Whole breath & $3.21(1.45-6.41)$ & $3.59(1.77-6.00) \dagger^{*}$ & $2.86(1.45-6.41)^{*}$ & $2.57(1.20-4.20)$ \\
\hline & Inspiratory & $3.03(1.44-6.56)$ & $3.38(1.79-5.27) \dagger^{*}$ & $2.56(1.44-6.56)^{*}$ & $2.47(1.14-3.76)$ \\
\hline & Expiratory & $3.41(1.52-7.66)$ & $3.72(1.73-7.66) \dagger^{*}$ & $3.08(1.52-6.26)^{*}$ & $2.69(1.26-4.84)$ \\
\hline & $\Delta R 20$ & $-0.29(-3.31-0.34)$ & $-0.32(-3.31-0.34)$ & $-0.28(-1.72-0.30)$ & $-0.28(-1.3-0.29)$ \\
\hline \multirow[t]{4}{*}{ R5-R2O (cmH $\left.{ }_{2} \mathrm{O} / \mathrm{L} / \mathrm{s}\right)$} & Whole breath & $1.22(-0.04-2.96)$ & $1.51(0.50-2.96) \dagger^{*}$ & $0.64(-0.04-1.83)^{*}$ & $0.25(-0.76-1.76)$ \\
\hline & Inspiratory & $0.82(-0.10-2.89)$ & $1.32(0.11-2.89) \dagger^{*}$ & $0.39(-0.10-1.99)^{*}$ & $0.11(-0.96-1.27)$ \\
\hline & Expiratory & $1.42(0.02-3.52)$ & $1.99(0.88-3.52) \dagger^{*}$ & $0.78(0.02-2.08)^{*}$ & $0.36(-0.57-2.24)$ \\
\hline & $\Delta(\mathrm{R} 5-\mathrm{R} 20)$ & $-0.50(-2.20-0.32)$ & $-0.68(-2.20-0.30)+^{*}$ & $-0.31(-1.05-0.32)$ & $-0.29(-1.15--0.04)$ \\
\hline \multirow[t]{4}{*}{ X5 $\left(\mathrm{cmH}_{2} \mathrm{O} / \mathrm{L} / \mathrm{s}\right)$} & Whole breath & $-1.23(-6.92-0.17)$ & $-2.77(-6.92--0.48)+^{*}$ & $-0.42(-3.50-0.17)^{*}$ & $-0.29(-1.48-0.20)$ \\
\hline & Inspiratory & $-0.78(-3.85-0.09)$ & $-1.57(-3.85--0.11) \dagger^{*}$ & $-0.42(-3.24-0.09)^{*}$ & $-0.33(-1.33-0.18)$ \\
\hline & Expiratory & $-1.63(-11.17-0.25)$ & $-3.74(-11.17--0.85) \dagger^{*}$ & $-0.37(-3.77-0.25)^{*}$ & $-0.23(-1.64-0.21)$ \\
\hline & $\Delta \times 5$ & $0.55(-0.47-8.50)$ & $1.80(0.59-8.50) \dagger^{*}$ & $-0.03(-0.47-0.54)$ & $-0.06(-0.37-0.48)$ \\
\hline \multirow[t]{4}{*}{ Fres $(\mathrm{Hz})$} & Whole breath & $13.74(4.23-26.52)$ & $19.61(7.91-26.52) \dagger^{*}$ & $7.97(4.23-25.96)^{*}$ & $6.53(4.03-14.89)$ \\
\hline & Inspiratory & $10.87(4.46-27.07)$ & $16.10(5.76-24.83) \dagger^{*}$ & $8.16(4.46-27.07)^{*}$ & $6.71(4.05-12.36)$ \\
\hline & Expiratory & $16.10(4.00-28.20)$ & $22.27(10.06-28.20) \dagger^{*}$ & $7.82(4.00-24.85)^{*}$ & $6.30(4.00-17.42)$ \\
\hline & $\Delta$ Fres & $-2.33(-15.00-2.98)$ & $-6.34(-15.00--0.08) \dagger^{*}$ & $0.14(-5.74-2.98)$ & $0.17(-5.37-1.75)$ \\
\hline \multirow[t]{4}{*}{$\mathrm{ALX}\left(\mathrm{cmH}_{2} \mathrm{O} / \mathrm{L} / \mathrm{s} \times \mathrm{Hz}\right.$} & tz) Whole breath & $7.44(0.04-62.87)$ & $22.16(1.96-62.87) \dagger^{*}$ & $1.42(0.04-33.88)^{*}$ & $0.92(0.01-7.64)$ \\
\hline & Inspiratory & $3.54(0.07-45.55)$ & $10.60(0.37-45.55) \dagger^{*}$ & $1.48(0.07-32.92)^{*}$ & $1.02(0.01-6.47)$ \\
\hline & Expiratory & $11.34(0.00-106.35)$ & $32.20(3.54-106.35)+^{*}$ & $1.19(0.00-34.83)^{*}$ & $0.74(0.00-8.87)$ \\
\hline & $\triangle \mathrm{ALX}$ & $-3.31(-86.95-2.35)$ & $-15.51(-86.95-0.00)+^{*}$ & $0.05(-5.73-2.35)$ & $0.15(-3.96-1.11)$ \\
\hline
\end{tabular}

Values are shown as a median (range).

Abbreviations: $A L X$ integrated low-frequency reactance area, $\triangle$ difference between inspiratory and expiratory phases, $E F L$ expiratory flow limitation, Fres resonant frequency, $R 5$ and $R 20$ respiratory system resistance at $5 \mathrm{~Hz}$ and $20 \mathrm{~Hz}, R 5-R 20$ difference between R5 and R20, X5 respiratory system reactance at $5 \mathrm{~Hz}$. ${ }^{*} p<0.05$ versus controls, $\mathrm{p} p<0.05$ versus low $\mathrm{EFL}$ index group.

better pulmonary function; however, there was no difference in the body mass index. Concerning forced oscillatory parameters, the control subjects had lower whole-breath, inspiratory, and expiratory R5, R20, R5-R20, Fres, and ALX values and less negative $\mathrm{X} 5$ values than patients with COPD; however, there was no difference in $\triangle \mathrm{Rrs}$, $\triangle \mathrm{X} 5$ (EFL index), $\triangle$ Fres, and $\triangle \mathrm{ALX}$ values between COPD patients with a low EFL index and controls.

We constructed a model from variables as follows: age, smoking history (pack-years), symptoms (mMRC and CAT), emphysema extent, spirometry (FEV1, FVC, FEV1/FVC, IC, and FEF 25-75\%), lung volumes (FRC, RV, TLC, and RV/TLC), and Rrs (whole-breath R5 and R20, and $\Delta R 5$ and $\Delta R 20)$. The univariate correlations between $\Delta X 5$ (EFL index) and predictor variables are shown in Table 3. $\triangle \mathrm{X} 5$ (EFL index) correlated positively with the mMRC scale, FRC, RV, TLC, RV/TLC, R5, and R20, and negatively with FEV1, FVC, FEV1/FVC, and FEF 25-75\%, but not with age, pack-years, CAT and emphysema scores, IC, $\Delta$ R5, or $\triangle \mathrm{R} 20$. Multivariate logistic regression analysis of the high EFL index $(\triangle \mathrm{X} 5)$ was performed using the selected model including 7 variables (AIC $=53.3$, Table 4$)$. The high EFL index was independently predicted by the emphysema score, FEF 25-75\%, FRC, and whole-breath R5, but not by mMRC, FEV1/FVC, and $\triangle R 5$. Unlike univariate analysis, multivariate analysis revealed that severe emphysema related to the high EFL index.

\section{Discussion}

We assessed whether emphysema extent and pulmonary functions contributed independently to the degree of EFL measured by broadband FOT in 74 patients with COPD. It was found that the high EFL index was independently predicted by emphysema extent as measured by HRCT, peripheral airway obstruction as expressed by FEF $25-75 \%$, hyperinflation as expressed by FRC, and airway caliber as expressed by whole-breath $\mathrm{R} 5$. These results suggest that EFL measured by FOT is a global measure of COPD 


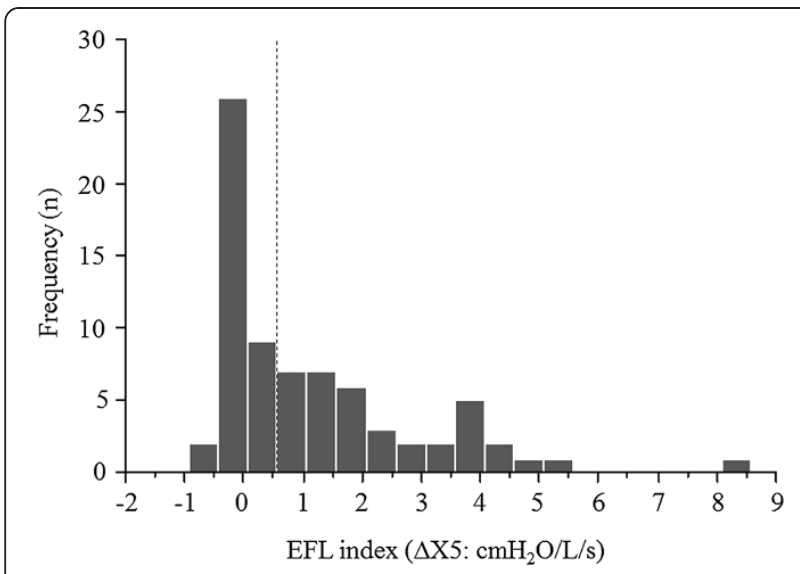

Figure 1 Frequency distribution of the EFL index $(\Delta \mathrm{X} 5)$ in $\mathbf{7 4}$ patients with COPD. The patients were classified into high or low EFL index groups according to the median value of $0.55\left(\mathrm{cmH}_{2} \mathrm{O} / \mathrm{L} / \mathrm{s}\right)$ (dotted line). Abbreviations: $\Delta \mathrm{X} 5$, difference between inspiratory and expiratory respiratory system reactance; EFL, expiratory flow limitation.

that has separable etiologies and therefore this could be used for stratifying patients and evaluating the severity of their disease or treatment response.

We consider respiratory impedance measured by FOT useful in research and clinical practice for the following reasons. First, it is performed during tidal breathing and does not require specific maneuvers or noticeable interference with respiration. Secondly, it provides information that is applicable to resting conditions or daily activities. Thirdly, it can be performed under different breathing conditions, such as deep expiration, and so provides information about the mechanical properties of the respiratory system that can be complementary to spirometry. Recent studies indicate that not only whole-breath but withinbreath analyses of respiratory impedance bring useful information on the pathophysiology of COPD and asthma. On the basis of the report by Dellacà et al. that $\triangle \mathrm{X} 5$ is a surrogate marker for EFL, we found that within-breath changes in Xrs ( $\triangle \mathrm{X} 5$ and $\Delta$ Fres) discriminated between patients with COPD and asthma [7]. Other investigators obtained similar results with the IOS, a slight different method of FOT from the method in the present study $[5,6]$. Thus, these results indicate that EFL measured by FOT is a useful measure to diagnose COPD.

In the present study, we confirmed that the emphysema extent as measured by HRCT was an independent predictor of the degree of EFL ( $\triangle \mathrm{X} 5)$, suggesting that reduced lung elastic recoil due to emphysema may be a cause of EFL. We previously showed that $\triangle \mathrm{X} 5$ values in 86 patients with COPD were significantly higher than those in 45 patients with pulmonary fibrosis, possibly because the latter has increased lung elastic recoil (mean, 1.23 vs $-0.18 \mathrm{cmH}_{2} \mathrm{O} / \mathrm{L} / \mathrm{s}$, respectively: $\mathrm{p}<0.05$ ) [8]. There have been only a few published studies concerning the relationship between respiratory impedance and emphysema on HRCT. Crim et al. found a poor

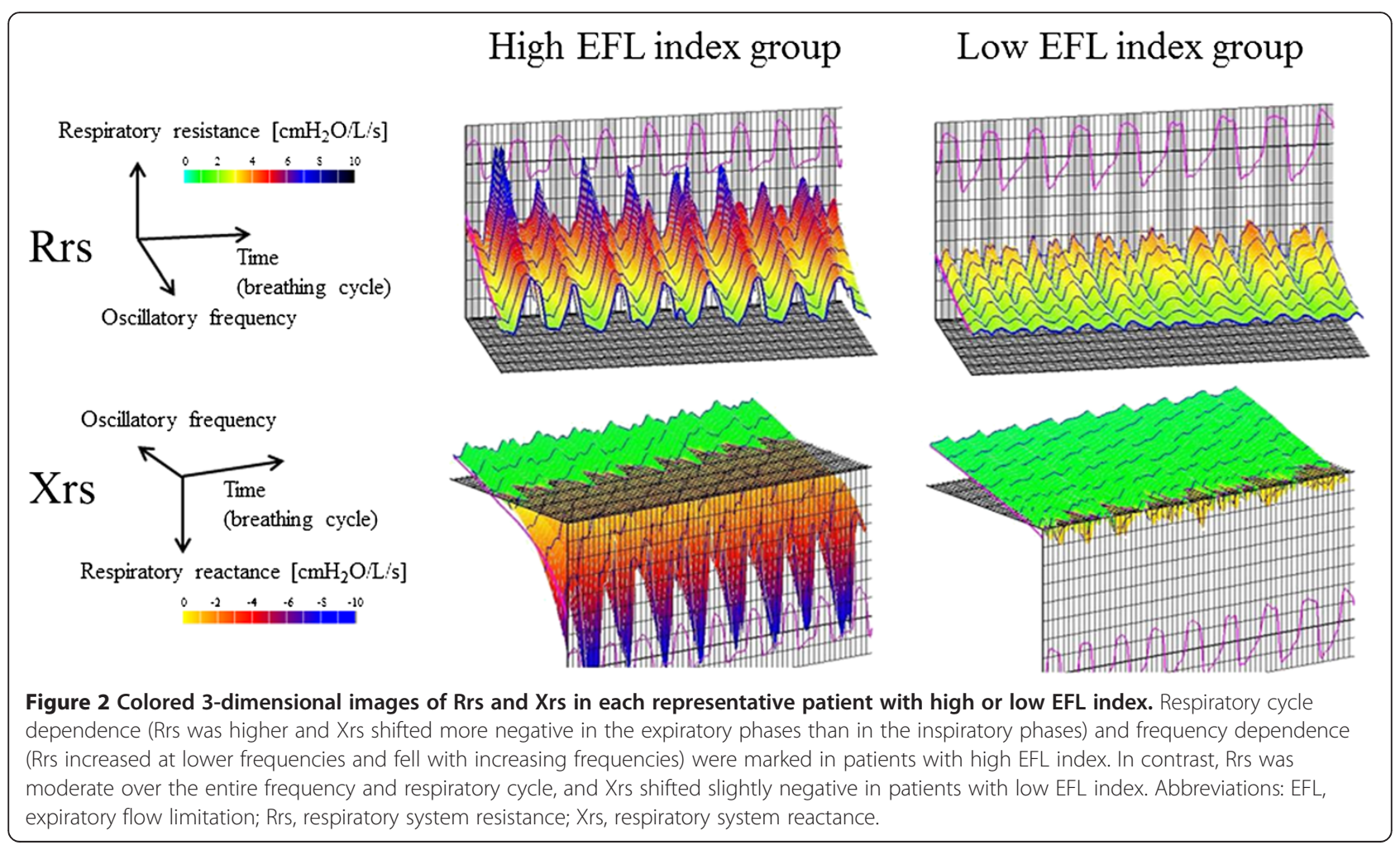


Table 3 Univariate correlations between $\triangle \mathrm{X} 5$ (EFL index) and predictor variables

\begin{tabular}{|c|c|c|}
\hline & Rho & $\mathrm{p}$ value \\
\hline Age (years) & 0.087 & 0.4556 \\
\hline Pack-years & 0.181 & 0.1217 \\
\hline mMRC scale & 0.282 & 0.0161 \\
\hline CAT score & 0.084 & 0.4712 \\
\hline Emphysema score & 0.107 & 0.3609 \\
\hline FEV1 (\% predicted) & -0.526 & $<0.0001$ \\
\hline FVC (\% predicted) & -0.365 & 0.0018 \\
\hline FEV1/FVC (\%) & -0.518 & $<0.0001$ \\
\hline IC (\% predicted) & -0.212 & 0.0707 \\
\hline FEF 25-75\% (\% predicted) & -0.640 & $<0.0001$ \\
\hline FRC (\% predicted) & 0.427 & 0.0003 \\
\hline RV (\% predicted) & 0.443 & 0.0002 \\
\hline TLC (\% predicted) & 0.245 & 0.0363 \\
\hline RV/TLC (\% predicted) & 0.448 & 0.0001 \\
\hline Whole-breath R5 $\left(\mathrm{cmH}_{2} \mathrm{O} / \mathrm{L} / \mathrm{s}\right)$ & 0.669 & $<0.0001$ \\
\hline$\Delta \mathrm{R} 5\left(\mathrm{cmH}_{2} \mathrm{O} / \mathrm{L} / \mathrm{s}\right)$ & -0.211 & 0.0709 \\
\hline Whole-breath R20 ( $\left.\mathrm{cmH}_{2} \mathrm{O} / \mathrm{L} / \mathrm{s}\right)$ & 0.528 & $<0.0001$ \\
\hline$\Delta \mathrm{R} 20\left(\mathrm{cmH}_{2} \mathrm{O} / \mathrm{L} / \mathrm{s}\right)$ & -0.007 & 0.9539 \\
\hline
\end{tabular}

Values are the Spearman rank correlation coefficient.

Abbreviations: CAT COPD assessment test, $\Delta$ difference between inspiratory and expiratory phases, $R 5$ and R20 respiratory system resistance at $5 \mathrm{~Hz}$ and $20 \mathrm{~Hz}, E F L$ expiratory flow limitation, FEF 25-75\% forced expiratory flow between 25\% and 75\% of FVC, FEV1 forced expiratory volume in 1 second, FRC functional residual capacity, FVC forced vital capacity, IC inspiratory capacity, mMRC modified Medical Research Council, NA not applicable, RV residual volume, TLC total lung capacity.

relationship (Pearson's $\mathrm{r} \leq 0.16$ ) between emphysema extent and Rrs and Xrs measured by IOS in a large study but they did not analyze within-breath changes [20]. Timmins et al. also reported that there was no correlation between emphysema extent and $\Delta \mathrm{X} 6$ measured by their in-house monofrequency FOT device [21]. Consistent with these reports, there was no correlation in univariate analysis

Table 4 Multivariate logistic regression analyses for predicting high EFL index

\begin{tabular}{lccc}
\hline Variables & $\begin{array}{c}\text { Adjusted } \\
\text { odds ratio }\end{array}$ & $\begin{array}{c}\text { 95\% confidence } \\
\text { interval }\end{array}$ & p value \\
\hline mMRC scale & 0.969 & $0.412-2.282$ & 0.9432 \\
Emphysema score & 1.296 & $1.013-1.659$ & 0.0395 \\
FEV1/FVC (\%) & 1.197 & $0.980-1.461$ & 0.0777 \\
FEF25-75\% (\% predicted) & 0.752 & $0.590-0.960$ & 0.0220 \\
FRC (\% predicted) & 1.108 & $1.039-1.181$ & 0.0017 \\
R5 (cmH $\left.{ }_{2} \mathrm{O} / \mathrm{L} / \mathrm{s}\right)$ & 3.426 & $1.470-7.983$ & 0.0043 \\
$\Delta R 5\left(\mathrm{cmH}_{2} \mathrm{O} / \mathrm{L} / \mathrm{s}\right)$ & 0.423 & $0.134-1.342$ & 0.1443 \\
\hline Abbrilons: & & &
\end{tabular}

Abbreviations: $\Delta$ difference between inspiratory and expiratory phases, $R 5$ respiratory system resistance at $5 \mathrm{~Hz}$, EFL expiratory flow limitation, FEV1 forced expiratory volume in 1 second, FVC forced vital capacity, FEF $25-75 \%$ forced expiratory flow between $25 \%$ and $75 \%$ of FVC, FRC functional residual capacity, mMRC modified Medical Research Council. in the present study, but multivariate analysis revealed that severe emphysema related to the high EFL index, indicating the need to control for confounding factors.

We also confirmed in the present study that wholebreath R5 was the strongest predictor of the degree of EFL $(\Delta X 5)$, but not $\Delta R 5$. Rrs reflects dissipative mechanical property of the lung [12], in other words, viscous resistance. As airway obstruction increases in COPD, Rrs rises and becomes more frequency dependent, especially at lower frequencies [22], implying that R5 is supposed to be a measure of airway caliber. Timmins et al. also found a strong correlation between R6 and EFL index [21], while Dellacà et al. confirmed that $\Delta \mathrm{R} 5$, in contrast to $\Delta \mathrm{X} 5$, was not associated with EFL [1].

There was an independent association between FEF $25-75 \%$ and EFL index; the lower the FEF $25-75 \%$, the higher the EFL index. When the flow-volume curve becomes more concave because of highly reduced flow in the effort-independent part of the curve, the degree of EFL increases; however, there was no association between FEV1/FVC and EFL index in multivariate analysis. These results suggest that the EFL index measured by FOT during tidal breathing reflects peripheral airway obstruction as measured by forced expiration. FRC, a measure of hyperinflation, was also an independent predictor of the EFL index in the present study, whereas Timmins et al. found no correlation. Possible explanations include the difference in the sample size or the FOT method.

We classified the patients into high or low EFL index groups according to the median value of the EFL index $\left(0.55 \mathrm{cmH}_{2} \mathrm{O} / \mathrm{L} / \mathrm{s}\right)$ of patients with COPD. Although all the control subjects had lower values than this cutoff level, this was not a genuine threshold value for detecting EFL. Dellacà et al. established a threshold value of $2.8 \mathrm{cmH}_{2} \mathrm{O} / \mathrm{L} / \mathrm{s}$ for the detection of $\mathrm{EFL}$, which was proven by esophageal manometry with high sensitivity and specificity [1]; however, our results were obtained with a broadband FOT device, MostGraph, whereas Dellacà et al. used their in-house monofrequency FOT. Therefore, the threshold value identified by Dellacà et al. may not be applicable to our patients and would have to be established for MostGraph by further studies.

Since the FOT device used in the present study can provide colored 3-dimensional images of respiratory impedance $[7,23]$, the difference in the images between patients with a high and low EFL index was distinct. This technique enables rapid perception of the disease condition rather than comparing each value, and would be useful if applied more widely in real clinical practice.

GOLD recommends the use of the mMRC scale or CAT to assess symptoms in patients with COPD; however, there was a difference in the analysis between these parameters in the present study. The univariate correlations in Table 3 showed that $\triangle \mathrm{X} 5$ (EFL index) correlated positively with the 
mMRC scale, but not with CAT score. Similarly, mMRC scale was higher in the high EFL index group than in the low EFL index group, but there was no difference in CAT score between the 2 groups. A possible explanation may be that the mMRC is a unidimensional measurement to quantify only dyspnea whereas the CAT score is a multidimensional method, which assess 8 items; not only dyspnea but also other symptoms and health status [24].

Methods for assessing EFL include not only FOT but also negative expiratory pressure (NEP), both of which are simple, noninvasive, and practical techniques [2]. A previous study found a good agreement between FOT and NEP despite some differences in detection of EFL [25]; however, the relationship between these techniques and NEP has not been fully understood. Further studies are needed to clarify this matter.

\section{Conclusions}

The risk of EFL is independently predicted by emphysema extent, peripheral airway obstruction, hyperinflation, and airway caliber. EFL measured by FOT is a global measure of COPD and is useful for evaluating the disease condition.

\begin{abstract}
Abbreviations
AIC: Akaike's information criteria; ALX: Low-frequency reactance; CAT: COPD assessment test; $\triangle$ : Differences between inspiratory and expiratory phases; EFL: Expiratory flow limitation; FEF 25-75\%: Forced expiratory flow between $25 \%$ and $75 \%$ of FVC; FEV1: Forced expiratory volume in 1 second; FOT: Forced oscillation technique; FRC: Functional residual capacity; Fres: Resonant frequency; FVC: Forced vital capacity; GOLD: Global Initiative for Chronic Obstructive Lung Disease; HRCT: High-resolution computed tomography; IC: Inspiratory capacity; ICS: Inhaled corticosteroids; IOS: Impulse oscillation system; LAA: Low-attenuation area; LABA: Long-acting $\beta 2$-agonists; LAMA: Long-acting antimuscarinic agents; mMRC: Modified Medical Research Council; Rrs: Respiratory system resistance; R5: Rrs at $5 \mathrm{~Hz}$; RV: Residual volume; TLC: Total lung capacity; Xrs: Respiratory system reactance.
\end{abstract}

\section{Competing interests}

The authors declare that they have no competing interests.

\section{Authors' contributions}

MM and TS contributed to the data collection and analysis, and writing of the manuscript. KM contributed to the data collection, analysis, and interpretation, and writing of the manuscript. YS, TA, SM, KA, and MF contributed to the data collection. TS contributed to the critical review of the manuscript and final draft. All authors read and approved the final manuscript.

\section{Acknowledgments}

We appreciate Dr. Hajime Kurosawa for his help.

\section{Author details}

'Department of Respiratory Medicine, Shizuoka General Hospital, 4-27-1 Kita-Ando, 420-0881 Aoi, Shizuoka, Japan. ${ }^{2}$ Second Department of Internal Medicine, Hamamatsu University School of Medicine, Hamamatsu, Japan.

Received: 28 June 2013 Accepted: 14 February 2014

Published: 19 February 2014

\section{References}

1. Dellacà RL, Santus P, Aliverti A, Stevenson N, Centanni S, Macklem PT, Pedotti A, Calverley PMA: Detection of expiratory flow limitation in COPD using the forced oscillation technique. Eur Respir J 2004, 23:232-240.

2. Koulouris NG, Hardavella G: Physiological techniques for detecting expiratory flow limitation during tidal breathing. Eur Respir Rev 2011, 20:147-155.
3. Hellinckx J, Cauberghs M, De Boeck K, Demedts M: Evaluation of impulse oscillation system: comparison with forced oscillation technique and body plethysmography. Eur Respi J 2001, 18:564-570.

4. Kurosawa H, Ohishi J, Shimizu Y, Tasaku Y, Kobayashi D, Masuda M, Kanezaki M, Nikkuni E, Kohzuki M, Hida W: A new method to assess lung volume dependency of respiratory system resistance using forced oscillation. Am J Respir Crit Care Med 2010, 181:A1240. www.goldcopd.org.

5. Paredi P, Goldman M, Alamen A, Ausin P, Usmani OS, Pride NB, Barnes: Comparison of inspiratory and expiratory resistance and reactance in patients with asthma and chronic obstructive pulmonary disease. Thorax 2010, 65:263-267.

6. Kanda S, Fujimoto K, Komatsu Y, Yasuo M, Hanaoka M, Kubo K: Evaluation of respiratory impedance in asthma and COPD by an impulse oscillation system. Intern Med 2010, 49:23-30.

7. Mori K, Shirai T, Mikamo M, Shishido Y, Akita T, Morita S, Asada K, Fujii M, Suda T, Chida K: Colored 3-dimensional analyses of respiratory resistance and reactance in COPD and asthma. COPD 2011, 8:456-463.

8. Mori K, Shirai T, Mikamo M, Shishido Y, Akita T, Morita S, Asada K, Fujii M, Hozumi H, Suda T, Chida K: Respiratory mechanics measured by forced oscillation technique in combined pulmonary fibrosis and emphysema. Respir Physiol Neurobiol 2013, 185:235-240.

9. Global strategy for diagnosis, management, and prevention of COPD. 2013. www.goldcopd.org. Date last updated: December 2011. Date last accessed: January 192013.

10. Bestall JC, Paul EA, Garrod R, Garnham R, Jones PW, Wedzicha JA: Usefulness of the Medical Research Council (MRC) dyspnoea scale as a measure of disability in patients with chronic obstructive pulmonary disease. Thorax 1999, 54:581-586.

11. Jones PW, Harding G, Berry P, Wiklund I, Chen WH, Leidy NK: Development and first validation of the COPD Assessment Test. Eur Respir J 2009, 34:648-654.

12. Oostveen E, Macleod D, Lorino H, Farré R, Hantos Z, Desager K, Marchal F, on behalf of the ERS Task Force on Respiratory Impedance Measurements: The forced oscillation technique in clinical practice: methodology, recommendations and future developments. Eur Respir J 2003, 22:1026-1041

13. Dellacà RL, Pompilio PP, Walker PP, Duffy N, Pedotti A, Calverly PMA: Effect of bronchodilatation on expiratory flow limitation and resting lung mechanics in COPD. Eur Respir J 2009, 33:1329-1337.

14. American Thoracic Society: Standardization of spirometry, 1994 update. American J Respir Crit Care Med 1995, 152:1107-1136.

15. Wanger J, Clausen $\mathrm{J}$, , Coates A, Pedersen OF, Brusasco V, Burgos F, Casaburi R, Crapo R, Enright P, van der Grinten CP, Gustafsson P, Hankinson J, Jensen D, Macintyre N, McKay R, Miller MR, Navajas D, Pellegrino R, Viegi G: Standardisation of the measurement of lung volumes. Eur Respir J 2005, 26:511-522.

16. Japanese Respiratory Society: Guidelines of respiratory function tests: spirometry, flow-volume curve, and diffusion capacity of the lung (in Japanese). Tokyo: Japanese Respiratory Society; 2004.

17. Tantucci C, Pinelli V, Cossi S, Guerini M, Donato F, Grassi V, SARA Study Group: Reference values and repeatability of inspiratory capacity for men and women aged 65-85. Respir Med 2006, 100:871-877.

18. Bottai M, Pistelli F, Di Pede F, Baldacci S, Simoni M, Maio S, Carrozzi L, Viegi G: Percentiles of inspiratory capacity in healthy nonsmokers: a pilot study. Respiration 2011, 82:254-262.

19. Goddard PR, Nicholson EM, Laszlo G, Watt I: Computed tomography in pulmonary emphysema. Clin Radiol 1982, 33:379-387.

20. Crim C, Celli B, Edwards LD, Wouters E, Coxson HO, Tal-Singer R, Calverley PMA, on behalf of the ECLIPSE investigators: Respiratory system impedance with impulse oscillometry in healthy and COPD subjects: ECLIPSE baseline results. Respir Med 2011, 105:1069-1078.

21. Timmins SC, Diba C, Farrow CE, Schoeffel RE, Berend N, Salome CM, King G: The relationship between airflow obstruction, emphysema extent, and small airways function in COPD. Chest 2012, 142:312-319.

22. Di Mango AM, Lopes AJ, Jansen JK, Melo PL: Changes in respiratory mechanics with increasing degrees of airway obstruction in COPD: detection by forced oscillation technique. Respir Med 2006, 100:399-410.

23. Shirai T, Mori K, Mikamo M, Shishido Y, Akita T, Morita S, Asada K, Fujii M, Suda T, Chida K: Usefulness of colored 3D imaging of respiratory impedance in asthma. Allergy Asthma Immunol Res 2013, 5:322-328. 
24. Kim S, Oh J, Kim YI, Ban HJ, Kwon YS, Oh IJ, Kim KS, Kim YC, Lim SC: Differences in classification of COPD group using COPD assessment test (CAT) or modified Medical Research Council (mMRC) dyspnea scores: a cross-sectional analyses. BMC Pulm Med 2013, 13:35.

25. Dellacà RL, Duffy N, Pompilio PP, Aliverti A, Koulouris NG, Pedotti A, Calverley PM: Expiratory flow limitation detected by forced oscillation and negative expiratory pressure. Eur Respir J 2007, 29:363-374.

doi:10.1186/1471-2466-14-23

Cite this article as: Mikamo et al.: Predictors of expiratory flow limitation measured by forced oscillation technique in COPD. BMC Pulmonary Medicine 2014 14:23.

\section{Submit your next manuscript to BioMed Central and take full advantage of:}

- Convenient online submission

- Thorough peer review

- No space constraints or color figure charges

- Immediate publication on acceptance

- Inclusion in PubMed, CAS, Scopus and Google Scholar

- Research which is freely available for redistribution 